\title{
The benefits of an extensive reading programme implemented in two Foundation Phase classrooms in the Eastern Cape, South Africa
}

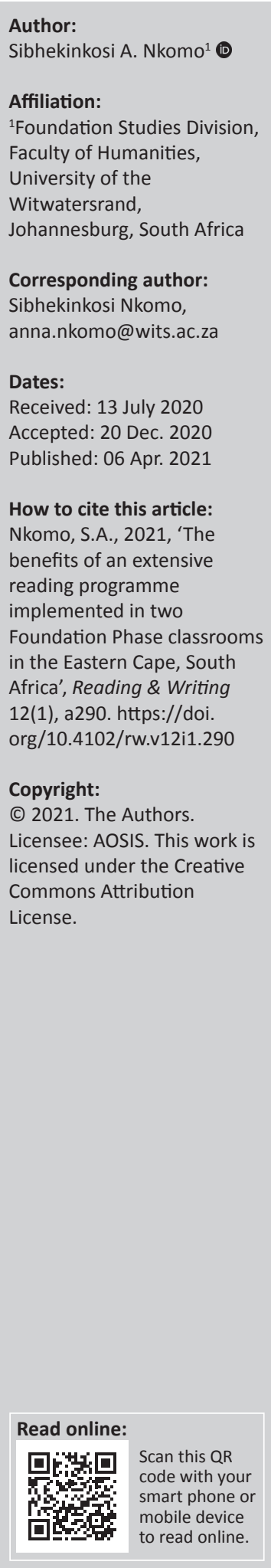

Background: This article reports on a responsive extensive reading programme (ERP), involving Grade 3 learners at two primary schools in the Eastern Cape over a duration of 20 weeks.

Objectives: The sociocultural perspective of learning guided the implementation of the ERP which aimed at providing learners with opportunities to read books for pleasure in their preferred language.

Method: Learners had a choice to talk about their reading in isiXhosa, their home language, or English, which is their first additional language. In supporting the long-term goal of being bilingual, learners were encouraged to see themselves as emergent bilinguals who have reasons to use both languages as young scholars and in future.

Results: Data collected through a post-intervention questionnaire, learners' reading logs and observations illuminated interesting findings which show that learners benefited from the ERP.

Conclusion: The benefits of participating in the ERP were observed in the learners' acquisition of new knowledge (cognitive benefits), transformation in their attitude towards reading (affective benefits), and they began to take agency of their reading (social benefits).

Contribution: This study demonstrates the cognitive, affective, and social benefits of introducing learners to reading for pleasure as early as in the Foundation Phase.

Keywords: literacy; extensive reading; early reading; Foundation Phase; Eastern Cape.

\section{Introduction}

South Africa is a multilingual country and it is expected that, through attending school, learners should reach certain proficiency levels and be able to communicate in more than one language (Department of Basic Education [DoBE] 2012). In South Africa, many learners are faced with the challenge of the language of learning and teaching (LoLT). In the Foundation Phase (FP) the instruction is in the learner's home language (HL), although at most schools English is taught as a first additional language (FAL). However, Spaull et al. (2016) state that by the end of FP, many South African learners lack the ability to read properly in their HL and the understanding of the English language in which they will be taught from Grade 4. In Grade 4, learners are expected to transition, not only from the use of the HL to English as the LoLT but also from learning to read, to reading to learn (DoBE 2008).

According to Le Cordeur (2010a), it is important to identify and address reading challenges such as poor reading comprehension, inadequate reading fluency, a lack of vocabulary, and a negative attitude towards reading as early as possible in the early years of schooling. In addition, literature has shown that many FP teachers do not know how to teach reading. They are currently teaching reading in an ad hoc, unsystematic way because of a lack of adequate professional development in effective strategies to address English learners' literacy development (Cekiso 2017; Le Cordeur 2010b; Pretorius \& Machet 2004; Taylor 2015; Van Staden 2011). Particularly in the rural areas of the Eastern Cape, Tshuma and Le Cordeur (2019) found that teachers had difficulties teaching in English due to their own lack of proficiency in the language. Of relevance to this study is the lack of access to appropriate reading resources in terms of language and genre, lack of reading opportunities, and an absence of a reading culture, which continue to disadvantage poor communities. 
Children from disadvantaged backgrounds have limited access to reading material compared to those from higher income families. According to Krashen (2004:68), 'children from high-income families are deluged with books, children from low-income families must aggressively and persistently seek them out'. Many underprivileged children in South Africa stay with illiterate guardians or parents who might not be able to read for them or who have limited time to read for them. Learners from poor communities do not have access or money to buy books written in African languages (Howie et al. 2007; Janks 2014), resulting in a poor reading culture (Pretorius 2002; Sisulu 2004).

For underprivileged learners, the school library is the only source for accessing reading resources, but some schools do not have a library. Sadly, both international (Neuman \& Celano 2001; Smith, Constantino \& Krashen 1997) and local (Equal Education 2011; Nassimbeni \& Desmond 2011) studies show that school libraries are largely dysfunctional and lack appropriate reading resources. For example, of the 5669 schools in the Eastern Cape, only 167 have functioning libraries (Equal Education 2011), leaving learners with little or no exposure to meaningful reading material. With little or no exposure to meaningful reading, children tend to refrain from the reading activity because they do not see the pleasure in reading and may not be proficient readers at all. Against such a backdrop, this article reports on the benefits of an extensive reading programme (ERP) implemented in two primary schools in Grahamstown over 20 weeks. The ERP aimed at instilling the love of reading by increasing reading time and offering a variety of reading material in both the learners' HL and FAL. A social learning environment was established where learners chose their own books and spoke about their reading in any language that they were comfortable in. In addition, the researcher provided learners with a variety of reading opportunities such as reading with them, reading for them, and allowing for individual reading or shared reading. This article ultimately responds to the research question: What are the benefits of an ERP for FP learners?

\section{Extensive reading}

Bamford and Day (2004) define extensive reading (ER) as:

$[A] \mathrm{n}$ approach to language teaching in which learners read a lot of easy material in the new language. They read for general, overall meaning and they read for information and enjoyment. (p. 1)

The purpose of ER is 'to develop good reading habits, to build up knowledge of vocabulary and structure, and to encourage a liking for reading' (Richards \& Schmidt 2002:193-194).

In ER, readers choose the material they are interested in, they read during their own time, at a pace and place comfortable for them. They read as much interesting material that is slightly below, at, or barely above their level of competence as possible (Krashen 2011). Despite ER being well documented and recognised as an important approach in teaching reading, it is often not given the attention it deserves in many formal educational contexts, and is simply tolerated as an add-on (Ramani \& Joseph 2002).

In the South African context, there has been little research conducted with FP learners in particular on the effectiveness of ER. Research into ER has mostly focused on the teacher or university students as the unit of analysis (Boakye 2017a, 2017b; Pretorius \& Knoetze 2012; Pretorius \& Machet 2004). The participants of the mentioned studies can read independently, with limited support from the teacher; therefore, findings from these studies cannot be extrapolated to learners participating in the current study. The current study fills this gap by supporting the view of children as active constructors of their own learning.

There are a number of studies that have reported positive gains through the implementation of an ERP (Boakye 2017b; Clark \& Rumbold 2006; Jacobs, Renandya \& Bamford 2000; Krashen 2004). Almost every study conducted to investigate the effect of ER on literacy development has reported positively about this approach, despite different methodologies and contexts.

In a review of works conducted mostly in well-resourced contexts in the global north, Jacobs et al. (2000) and Krashen (2004) summarised a number of experimental studies that show significant increase in vocabulary, comprehension, spelling, writing, listening skills, and academic performance as a result of ER. Simon (2018) and Boakye (2017) also reported overall cognitive benefits of ER which included increased reading speed in their participants.

Extensive reading can also have benefits on the affective aspects of reading such as attitude, motivation, and interest. Learners become motivated to read because of the rich input they receive when reading their self-selected books (Krashen 2004). According to Gambrell (2004), when learners are given enough time to read for pleasure they become more creative and critical thinkers. Reading for pleasure can contribute to positive attitudes and increase self-confidence. Boakye (2017b) included the ER component in her reading intervention programme to improve firstyear university students' reading proficiency who were registered for the Academic Literacy and Academic Reading modules. Her study points out that ER impacted on the students' affective and cognitive reading levels, including reading speed.

In summary, the benefits of ER are captured by Day and Bamford (1998) when they state:

Good things happen to students who read a great deal, they become better and more confident readers, they write better, their listening and speaking abilities improve, and their vocabularies become richer. In addition, they develop positive attitudes toward reading and increased motivation to study the new language. (p. 1) 


\section{Theoretical framework}

The sociocultural perspective of learning (Vygotsky 1978) guided the implementation of the ERP. This Vygotskian perspective was appropriate for this study because it implies that learning happens in a social and collaborative context where learners interact with other people and objects, and can also get some form of help through scaffolding from peers and teachers (Vygotsky 1978). Adopting this view, the researcher established an ERP in a social learning environment that emphasised collaborative learning and emancipating the participants. I scaffolded and mediated learning using tools (language and books) so that learners could actively participate and eventually be in a position to independently take charge of their learning. Within the reading programme, the role of the researcher was fluid. Roles such as managing the attendance register and the accession register were shared by the participants and the researcher. In addition, there was co-construction of knowledge, thus acknowledging the participants as equally knowing.

Since the study is about literacy development, the sociocultural theory is relevant in that Vygotsky (1978) emphasises the importance of language in development and learning. According to Krashen (2004), when children read in their $\mathrm{HL}$, they understand the subject matter better. Skills learnt in their HL are easily transferable to their FAL. Therefore, in this study, language was considered as a mediating tool for subjects to encourage reading for pleasure, which was the object of the ERP. By mediating tools Vygotsky (1978) meant artefacts that can include language and books. The subjects are the individuals engaged in the activity (Grade 3 learners) and the object is the goal of the activity.

In the informal learning context established in this study, interaction happened at different levels, namely learnerlearner and researcher-learner. While working with young bilingual children (isiXhosa and English language learners), I found language, in all its forms of use (writing, reading and speaking), to be an important tool in mediating and facilitating interaction, participation, and learning. According to Vygotsky (1978), language is a mode of communication that people use to interact with each other to convey information, transfer knowledge, and to support cognitive development. Hence, in this study, a reading programme that accommodated the use of learners' HL and FAL was established as a means of facilitating learning, social participation, and interaction. Strategies like codeswitching, translation, and translanguaging were encouraged by the researcher in this setup. In addition, I allowed learners to use visual and multimodal forms of communication. As a result, interaction was not merely possible, but was more relaxed and spontaneous, as learners were able to engage in discussions and solve problems among each other or with the researcher.

\section{Research paradigm}

The study is located under the interpretivist paradigm, mainly because it allows the researcher to interpret the world through the views and understandings of the participants. The objective of the study was to implement and closely assess the impact of the reading programme. The interpretive methodology allowed me to engage with my participants, listen to their views and perspectives.

\section{Research methodology}

The study employed mainly qualitative methods such as observations, reading logs, and a questionnaire.

Observations involved observing learners in a variety of activity structures such as independent reading, silent reading, reading aloud, book talks, and focus group discussions. Indicators such as the number of books read, reading behaviour such as comfort and anxiety in reading, active participation and engagement, expressed interest as well as lack thereof, and attitude, were used to inform the observational judgment. According to Clay (1991):

[O]bservation of children's responses to reading and writing is a useful research tool, as it provides one with information concerning their competencies, confusions, strengths and weaknesses, and their use of strategic activities. (p. 70)

Reading logs were used for data collection. The information recorded by the learners included book titles, name of the author, date when the book was read, and a section where learners commented about what they liked or disliked about the book. According to Carlisle (2000), a reading log is a simple tool that can be used to encourage and tap into individual learners' responses to a text. This encourages them to interact with the text. A reading log provides valuable information which can inform one about what learners read.

A post-intervention questionnaire was designed and administered with all the participating learners. The questionnaire was availed to the participants in both languages isiXhosa (HL) and English (FAL). On realisation that not all learners were proficient readers, each question in the post-intervention questionnaire was read out in both languages and learners were required to write down their responses. Learners got a chance to hear the question being read out, they also read the question for themselves, and they were given enough time to process each question and respond.

\section{Setting}

The study was conducted in two Grahamstown public primary schools. Labelled as site A and site B for ethical reasons, both schools are historically disadvantaged and located in the township. They serve children who are from poor socio-economic backgrounds. In both schools, isiXhosa, which is the learners' HL, is used as a medium of instruction until Grade 3, after which learners switch to English. 
Site A has a well-resourced functioning library, but learners have limited access to it because the school does not have a librarian. As Malespina (2016) puts it:

[A] library is not a library without a librarian, as [librarians] will always be the necessary bond between the space, the tools and resources and the students and teachers accessing them. (p. 1)

Site B had no library facility and, as a result, learners have little or no exposure to meaningful reading material beyond their textbooks and workbooks.

\section{Study population and sampling strategy}

The participants in this study were Grade 3 learners. Two key reasons accounted for choosing the grade of participants for this study. The first is that this group of learners is at a critical juncture where they are shifting from learning to read to reading to learn (DoBE 2008). In the FP, learners are developing the skill and art of reading but when they move to Grade 4 they are expected to read different content subjects and learn from what they read. Reading in the FP is mostly narrative, story-like texts whose language closely approximates ordinary language of everyday social interaction, as compared to reading expository texts with more content-dense vocabulary in Grade 4 (Chall, Jacobs \& Baldwin 1990). This group of learners may benefit from a reading programme that would expose them to reading and talking about books in both their HL and FAL so that they would have a chance to transition from learning to read to reading to learn in Grade 4. The second reason relates to them transitioning from mother-tongue instruction to learning through English, their FAL. This abrupt switch has a possibility of influencing their attitude towards reading negatively.

Since the participants were minors (Grade 3), consent was sought from their parents or guardians. Consent forms and information sheets were availed in English and isiXhosa to ensure informed consent. In addition, learners were verbally informed about the purpose of the reading programme, the nature and extent of their involvement. However, only those learners with signed consent forms from their guardians were allowed to be part of the study and participation was voluntary. In site A, all 37 learners (17 girls and 20 boys) had signed consent forms and all 34 learners (16 girls and 18 boys) from site B participated.

\section{The intervention: Conceptualisation and implementation of an extensive reading programme}

Implementing an ERP that stretched over 20 weeks was a form of formative intervention (Engestrom 2011). Formative intervention methodology is based on the principle of taking the process into account as much as an outcome (Daniels 2001). Accordingly, the researcher encouraged learners to be active participants rather than passive listeners. The formative intervention implemented created openness for the learners by providing opportunities for learners to read alone, to be read to, and to read for each other in a way that made sense to them. Four steps guided the implementation of the ERP.

\section{Step 1: Pre-intervention - sourcing of reading resources}

Prior to the implementation of the ERP, books were sourced from Biblionef, the Nal'ibali reading resources, and the researcher's personal collection. The book stock included different genres, non-fiction, magazines, newspapers, fiction, texts that inform, and texts that entertain which were appropriate for a Grade 3 learner. For the most part, the books were about 10 pages and included illustrations and drawings. Having a wide selection of reading material managed to cater for many of the learners' book and language preferences. The study was conducted according to the guidelines of the institution and the Department of Education. In particular, consent was obtained from the participating schools' principals, teachers, and the learners' parents or guardians

\section{Step 2: Setting up the extensive reading programme}

The setting up of the ERP was over the first two school terms and can be summarised as follows:

- Explaining to the teachers and participants the ways in which the reading programme was to become a regular routine throughout the year. Ethical clearance was sought.

- Explaining the reasons for ER and of the reading programme.

- Highlighting the requirements and principles of an ERP.

- Laying down ER ground rules.

- Deciding on the appropriate venue and on the convenient times to conduct the reading programme. We agreed that we would meet in the learners' classroom, once a week, for an hour after school so as not to disturb the normal school teaching programme.

I had initial reading sessions with all the learners at both sites to build trust and to prepare them for the actual implementation of the reading programme. I went to the schools during term 2, once a week after school to read for the learners as a whole class activity. Thereafter, we had book talks, discussing what they liked and did not like about the story I had read. This stage of the research offered me an opportunity to introduce learners to a variety of genres written in English and isiXhosa.

\section{Step 3: Implementation of the extensive reading programme - design and structure}

Learners were encouraged to read any books provided by the researcher or their own books if they had any and either during the reading session or outside of it. Those who could not read on their own were encouraged to take books and ask either the researcher, their peers or other people at home to read for them.

Depending on the weather conditions, each reading session was held in the learners' classroom or outside (Figure 1). I set time for reading for the learners, reading with the learners, and reading by the learners. Each week, I expected each learner to have read at least one book so that by the end of the 

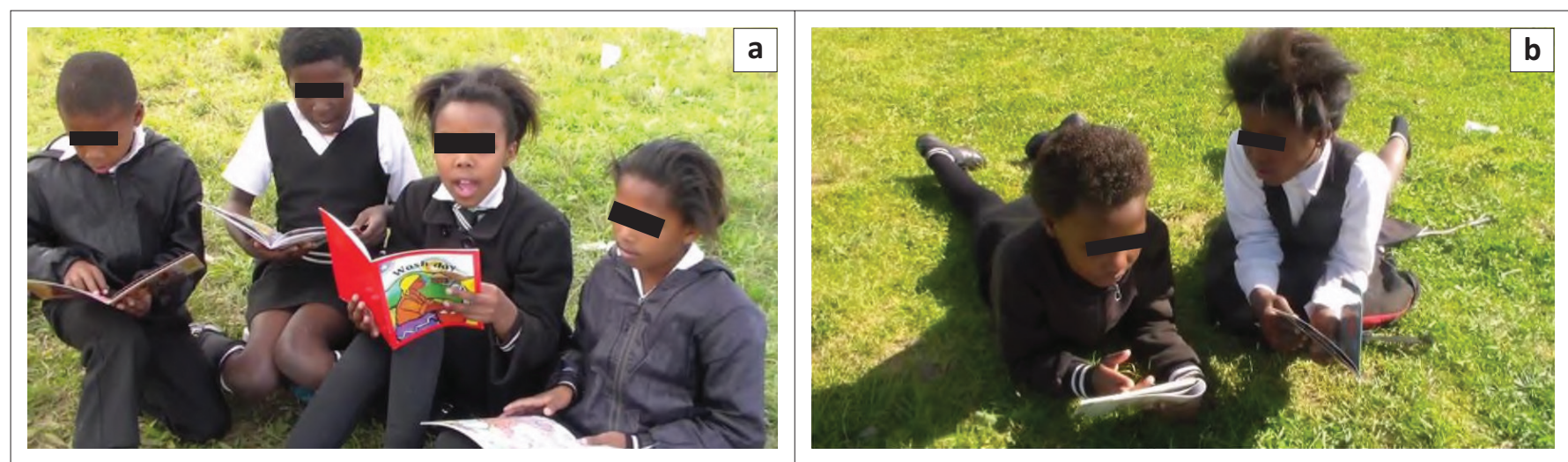

Source: Photographs taken by and published with permission from Gladys Tyatya (research assistant), Grahamstown, South Africa.

FIGURE 1: Learners reading outside of their classroom ( $a$ and $b$ ).

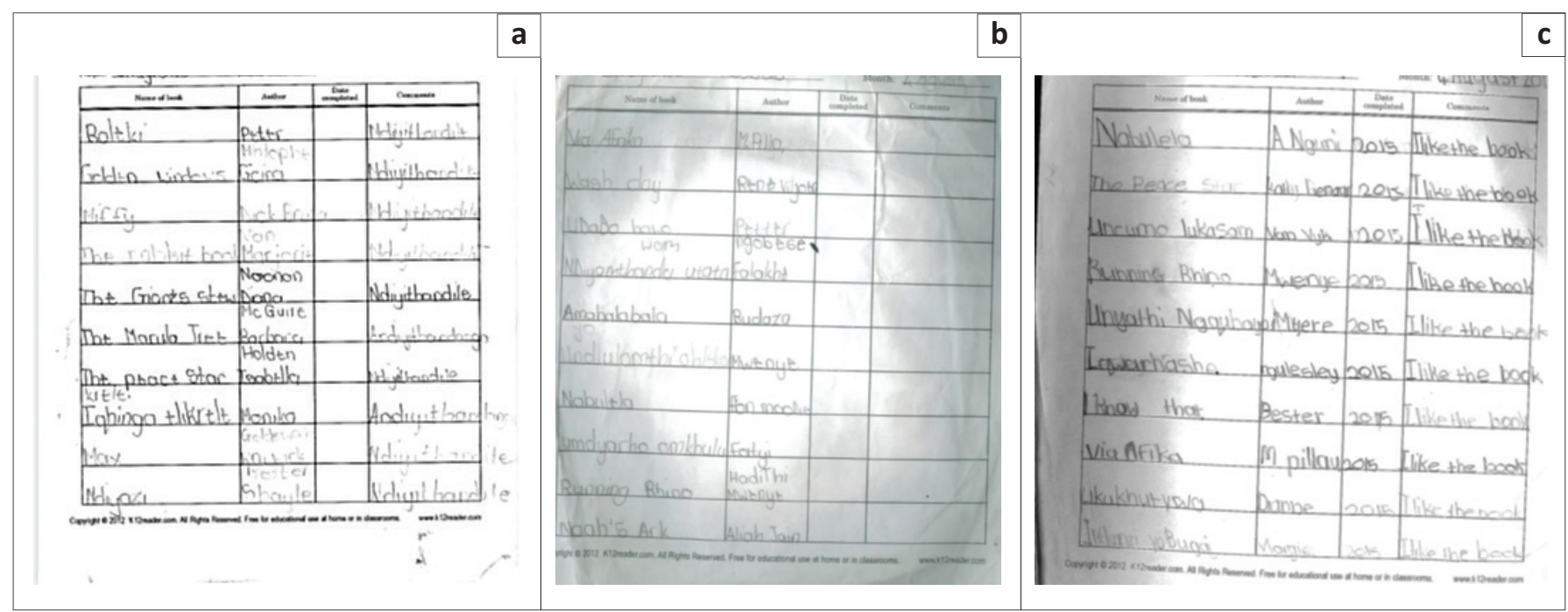

FIGURE 2: Learners' reading logs: (a and b) example 1 (c) example 2.

intervention, each learner would have read at least 20 books. Having a target number of books per week has proven to be motivating for some learners; however, one should be careful of setting strenuous goals to read, as the real goal of ER is to enjoy reading.

Ideally, in an ERP, no post-reading work should be required as the act of reading is its own reward. However, for this study, there were reasons for considering post-reading activities. These include the need to monitor and evaluate learners' reading in order to determine if the learners were actually reading, understanding, and learning from the reading. Another reason for considering post-reading activities, as suggested by Day and Bamford (2002), is that well-chosen activities can turn the individual solitary act of reading into a community event especially for young children.

The ERP had carefully planned typical ER post-reading activities suggested by Day and Bamford (1998). These included book talks, reading aloud, paired and shared reading. In addition, learners were required to submit a reading log. Participating in these activities was optional and learners were allowed to use whichever language they were comfortable in so as to encourage bilingualism and participation. Morrow and Schocker (1987) make the point that:

$[A]$ personal response to a text in ... [a] foreign language is likely to be 'felt' in the native language. Attempting to mediate the response through a foreign language will merely lead to frustration. (p. 255)

Indeed, I observed that giving learners an opportunity to express themselves in their HL yields good conversations and inclusive participation. Hence, the use of HL became a powerful tool that boosted learners' desire to speak, read, and write.

Finally, it was important to provide feedback to the learners throughout the ERP. In each reading session, I had an opportunity to observe and interact with the learners to get their perspectives about the reading programme. I also looked at their reading logs, to see what they were reading (Figure 2). Permission was sought to videorecord each reading session. At the end of each session I would replay the video noting any attitudes to reading and literacy such as anxiety in reading, active participation, engagement, and expressed interest as well as lack thereof. In some instance, I would require the learners to further explain or clarify their 
actions that I observed on the video recordings. I attended to the learners' needs individually or as a group. Providing feedback in these different setups (individually and in groups) was done for specific reasons and was beneficial to the learners. For example, if I felt the learner needed one-onone assistance, or if I did not want to put the learner in the spotlight, I would call the learner aside and work with them. In some instances, if I wanted learners to participate in meaningful discussions, or if I noted that they all experienced the same problem, for example writing in their journal, I would model, demonstrate, and provide feedback to the whole group.

\section{Step 4: Evaluation of the extensive reading programme}

The final phase of the research process was the evaluation of the ERP and was conducted during the last week of the intervention. This phase aimed at responding to the research question: What are the overall benefits (if any) of an ERP on FP learners? The main tool used for evaluation was the postintervention questionnaire although I also relied on other methods such as the reading logs and my observations. The purpose of administering this questionnaire was mainly to evaluate the programme, and to see whether the aims of the programme were achieved. In site A, 27 out of 37 learners responded to the questionnaire, while 23 out of 34 learners in site $\mathrm{B}$ responded.

\section{Data collection}

The data was collected through a reading log, observations, and post-intervention questionnaire.

The questionnaire was administered with all the participating learners. Questions asked on the questionnaire included:

- How many times (roughly) have you attended the reading programme sessions this year?

- Why did you attend the reading programme?

- How many books did you read throughout the programme?

- Which was your favourite book and which one was your least favourite?

- Over these past school terms, do you think that coming to the reading programme sessions has helped you with your reading? Please say how?

- Has attending the programme helped you with your other schoolwork? Can you say how and in which subjects?

- What have you enjoyed at the reading programme sessions?

\section{Data analysis}

To qualitatively examine the overall benefits of the ERP, I used content analysis to analyse data collected through questionnaires, learners' reading logs, and my observations. In this study, data were broken down and coded into themes that addressed the cognitive benefits of extensive reading (What new information did participants learn?), affective aspects such as attitude (Did they change the way they think or feel about reading?), and behaviours (Did they change or transform their activity, i.e. take agency with their reading?).

\section{Presentation and discussion of results}

Data from the questionnaires represent the learners' voices about how they believe ER was beneficial to them. Learners reported in their HL, and I translated the excerpts quoted in this article into English. My observations and information on the learners' reading logs are presented to provide further insight into how ER had effects on both the cognitive and affective aspect of reading. The three data sets are provided for triangulation.

\section{Observations}

Through observation, I noted that learners from both research sites were actively engaged in learning and reading-related activities, an indication that they had positive attitudes towards the reading programme. Most of the Grade 3 learners who participated in the programme were enthusiastic about reading and looked forward to the next session. Learners were interested in reading with their friends, and spending time reading and growing together. This enthusiasm cannot be overlooked in an educational setting. It is important for children to learn that reading is a social activity, which can be done anywhere, not just something that teachers make you do only at school, at a particular time. Reinforcing this point, Spaull (2014) states that children must be motivated regularly to view reading as a pleasurable activity.

I noted an improvement on the affective aspect of reading such as motivation and interest in books in both research sites. I also observed enjoyment, excitement, passion, improved confidence, and engagement because of the increased opportunity to read through the ERP. The agency of the learners especially from site B to read and begin their own reading circles was unexpected. Over the 20-week reading intervention, learners from both research sites who regularly attended the reading programme developed from being shy, reserved, and uncertain readers into readers who could try to read what was of interest to them. They began to talk about their reading and responding to books they had read, and the characters they liked and did not like. Each learner's views were valued, hence each reading session became a platform of growth. These observations of the development of the participants' agency as readers were neatly summed up in the researcher's journal.

\section{Reading logs}

Research has shown that the number of books read by each learner during a reading programme is important in determining if the reading programme was a success (Day \& Bamford 2002). To track the number of books read by each learner, I relied on the participants' reading logs. 
Some learners, who prior to implementation had never read and completed a book, reported to have read and enjoyed at least two books. As shown in Figure 3, data collected from learners who recorded their reading in their reading logs show that over a duration of 20 weeks of the implementation phase, the highest participants read 20 books and the lowest read 2 books in both sites. Based on the increased usage of the books availed, there is evidence that the participants' reading behaviours changed towards reading for pleasure. The majority of the learners began to read more during each reading session and began to take books home for reading and were able to report back on their reading. By the end of the programme, voluntary reading happened regularly in both research sites.

Evidence from the accession register and the reading logs showed an increase in number of learners borrowing books (Figure 2). The reading log example 1 in Figure 2 shows a learner who read and entered 20 books in her reading log. Morrow and Weinstein's (1986) study findings show that children read more when there is more material available for them to read.

Allowing learners to borrow books from the programme provided opportunities for learners to read beyond the reading programme. For example, in site A, one learner struggled with reading on her own and I encouraged her to take books home, and read with her parents or siblings, a noteworthy factor in the promotion of reading for enjoyment. I believe that the time learners spent reading with parents offered the parents an opportunity to see what their children were interested in reading. One learner reflected in her journal about how much she enjoyed the story and even enjoyed reading to her siblings and parents. This enhanced her self-esteem and gave her an opportunity to enjoy and bond with her family:

Date: 11 November 2015

Title: Tsepo

Author: Beate Willich

Who was it about? Tsepo.

Dear Beate [addressing the letter to the author], your book was very interesting, it was informative. In the book Tsepo you narrate so well and your illustrations talk about a lot of things. Tsepo did not have so many things but his brother gave him. Your book was very interesting Beate, I even read it for my parents and siblings at home every day. Every evening before they went to bed they asked me to read for them. Thank you.

According to Chambers (2011), everyone enjoys freedom of choice and:

[W] hen we have freedom our set of mind, that is our attitude, tends to be optimistic and positive. We cheerfully become willing readers when following our own instincts and tastes. (p. 31)

I would argue that availing a range of reading texts in this ERP positively influenced learners' reading attitudes and motivation to read. As shown in their reading logs (Figure 3), learners appreciated that there was a reasonable number of books written in their mother tongue.

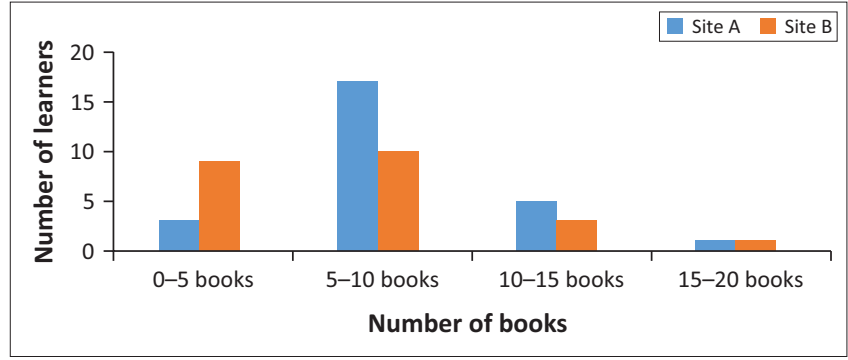

FIGURE 3: Number of books read by learners.

Learners preferred to read the isiXhosa version of the books. This is understandable because at this stage they are still using their mother tongue as a language of learning. However, as the session progressed, I had three learners in site A and two in site B who began to read books in English. These included simple and interesting books like I love my father and The Red Hen. When it came to other forms of communicating, learners were encouraged to communicate using both their HL and FAL, but I noted a number of learners opted to read, speak, and write in English even though they were not proficient. In both research sites, learners are aware of the importance of being bilingual and being able to communicate in English. Learners' preference for English in these research sites is consistent with what Bloch (2007:50) found: 'the pressure to opt for the ex-colonial language associated with its economic power and prestige, manifested in teachers' preferences and parents' and children's demands'.

\section{Post-intervention questionnaire}

Through the post-intervention questionnaire, all learners from both research sites acknowledged that they had benefited from participating in the programme. On a more specific level, question 2 of the questionnaire required learners to provide reasons why they continued attending the voluntary ERP. In both research sites, the three most frequent responses were academic gains associated with reading, the need to learn how to read so as to achieve at school, and the social aspects of the ERP. With reference to academic gains associated with reading, one student wrote 'I attended the club because being able to read will allow me to go to university and get a good job'.

From site B, three boys mentioned they attended the reading programme because they just wanted to. These three boys would irregularly attend the reading programme as they were aware that they were not obliged to attend. Other learners expressed the need to learn how to read. One learner wrote 'I attended the reading programme because I want to learn to read in English'. Another learner wrote 'I can't read properly, I wanted you to teach me how to read so I attended every day'. Finally, all the learners in both sites agreed that they enjoyed attending the reading programme because it was fun, which is a social aspect of the reading programme and they also highlighted their intrinsic love of reading. The social learning environment established was encouraging for the learners to attend the reading programme. Grabe (2004) 
claims that if implementation conditions are reasonable, ER creates positive motivation for reading.

In responding to the question about how the programme has helped them with other schoolwork, three learners from site A indicated that the ERP improved their reading while four learners indicated that the ERP helped them improve in other subject areas. In addition, from this research site, four learners indicated that their isiXhosa improved since attending the ERP, and two learners mentioned that they had improved reading in English. Since learners had a choice of using both their HL and FAL, it was interesting to note that two learners from this site indicated that the ERP helped them to read in both English and isiXhosa. Learners from site $B$ also indicated their different gains through attending the ERP. Nine learners indicated that the ERP helped them with reading and writing in isiXhosa, while six learners indicated that the ERP helped them with reading and writing in English. Two learners indicated that the ERP helped them improve their life skills but did not elaborate on that. However, these claims are based on the learners' perceptions of what they gained by participating in the programme and could not be validated through assessment as it was beyond the scope of the research. Pretorius and Lephalala (2011) state that learners from print-poor backgrounds might improve their language proficiency when exposed to a reading intervention

In responding to what they had enjoyed from the reading programme, all learners, including the ones who were initially reluctant, stated that the reading material offered was interesting and they enjoyed reading the books. Their interest in reading was seen in the number of books recorded in their reading logs (Figure 2). In site B, seven girls who stayed in the same neighbourhood formed a reading circle which was active throughout the duration of the reading programme. Individual learners who could not form their own reading circles preferred to borrow more books from our book stock to take home. Implementing an ERP in the two FP classrooms was a useful experience as I observed that if learners are given the opportunity and encouragement to read they can see the pleasure in reading and want to read more. Reduced reading opportunities means that learners' competence and confidence both suffer. There is enough evidence showing that ER done consistently over a long period of time leads to positive reading attitudes and improved abilities in several language areas (Grabe 2009).

Le Cordeur (2010b) identifies negative attitude as one of the various types of reading problems. By including a variety of ER activities, I observed positive attitudes towards reading. For example, learners looked forward to my reading aloud session 'because they enjoyed how I read in English'. In addition, they began to volunteer to report about their reading and leading the book talks. All the participating learners from both research sites mentioned that they enjoyed being part of the ERP and that they would appreciate another opportunity to participate in the ERP. Although learners from both research sites felt the need to attend the reading programme for different reasons, overall they all saw the value of the reading programme. This concurs with other findings (Elley \& Mangubhai 1983; Krashen 2004) that an ERP has a significant effect not only on reading ability but also on other skills and motivation to read.

The last question of the questionnaire offered the learners an opportunity for free writing. This could be a message, letter to the researcher or a brief reflection about the ERP. These are some of the statements that I gathered which show how the programme was beneficial to the learners.

In site A two learners wrote:

Learner 1: 'Dear ma'am, I enjoyed each time when you read for us. Thank you'.

Learner 2: 'Miss Anna, you read well. I appreciate your support. I learnt a lot. Thank you very much'.

In site B, two learners wrote detailed letters which captured a number of the benefits of the ERP:

Learner 1: 'Thank you for teaching me how to write. Now I know how to write and read the stories that I chose and they give me joy when I read them. Thank you very much. Please go well, thank you very much'.

Learner 2: 'Beloved diary: (1) I liked your programme. Because it's educative. (3) Reading is fun'.

An overall analysis of the results indicates that daily exposure to ER was beneficial to participants. They highlighted the cognitive and affective benefits of the ERP. The benefits of ER reported in this study are supported by the literature about the advantages of exposure to a reading intervention.

\section{Implications or recommendations}

Informed by the findings of this study, the following recommendations can be made: learning to read and reading to learn must happen at the same time across all primary year levels, beginning in the FP. This may actually increase learners' motivation and interest to read. As asserted by Le Cordeur (2010), reading should be part of every child's daily experiences so that parents and teachers can identify a child with reading problems and address these early.

In addition, learners should be exposed to a variety of text types at an early age. This may provide teachers with information regarding learners' attitude towards reading and their engagement with reading so they may offer intervention programmes at an early age. Reading for enjoyment needs to be prompted at an early age and positively celebrated both at school and at home. It is evident that for learners to get motivated to read and value any reading activity, they must be immersed in an environment that offers a variety of interesting reading activities. Such an environment enables learners to be scaffolded in their learning and, as a result, they develop positive attitudes towards reading and see themselves as readers. 
A range of text types should be availed for learners of all ages to engage in a variety of reading activities and for the teachers as well to use during shared reading. It is important to find appropriate books in learners' HL and FAL so as to stimulate their interest in reading. Lack of access to and availability of interesting reading material might lead to the decline of reading attitudes. Therefore, there is a need for functioning school libraries, community libraries, and classroom reading corners. According to Guthrie and Wigfield (2000), the use of a range of texts in the classroom can stimulate learners' curiosity and provide the motivation needed by some learners to read. Oyegade (2012) states that if reading habits are to be improved, then learners have to be able to access books at any time.

The successful implementation and sustainability of a reading intervention would have a lasting impact if there is support from the school management. A mediator or facilitator (agents of change) should be available to stimulate learners to find the joy of reading, thus developing readers. This means that 'a more knowledgeable other' has a significant role to play in developing children as readers. They act as role models and value the importance of participating in a culture of reading, thus learners will thrive in an environment that values and encourages reading.

\section{Conclusion}

This article has provided insight into how an ERP encouraged reading for enjoyment and helped improve Grade 3 learners' cognitive and affective aspect of reading. The small gains in the cognitive aspects of reading in this study may be ascribed to insufficient time for doing ER. Research indicates the longer the duration of the intervention, the better the chances of success. Data collected throughout the study show that learners benefited from the ERP. The post-intervention questionnaire shows that the learners believed that they had developed their reading and writing skills which they transferred to other learning areas. The data also show that the ERP had an impact on the learners' motivation, interest, and attitude towards reading, hence they began to take ownership of their reading by forming reading circles and borrowing more books. It is therefore concluded from the findings that ERP can instil the love of reading in learners and thus increase the learners' affective levels in reading as well as behavioural changes. Even if the results of this study do not explicitly confirm gains in reading speed and vocabulary, learners' positive attitude towards reading for pleasure cannot be overlooked. It must be noted that this is a small-scale study and hence the findings are not generalisable. They show what happened in this particular context. Nevertheless, they give important and authentic insights into the impact of an ERP on the cognitive, affective, and social domains of reading.

\section{Acknowledgements}

The author would like to thank the Grade 3 learners from the two research sites for their participation in this study and their permission to use data collected throughout the research process.

\section{Competing interests}

The author declares that she has no financial or personal relationships that may have inappropriately influenced her in writing this article.

\section{Author's contribution}

S.A.N. is the sole author of this research article.

\section{Ethical considerations}

This article followed all ethical standards for carrying out research, with approval from the Faculty of Education Higher Degrees Committee, Rhodes University.

\section{Funding information}

The research received no specific grant from any funding agency in the public, commercial, or not-for-profit sectors

\section{Data availability}

The author confirms that the data supporting the findings of this study are available within the article.

\section{Disclaimer}

The views and opinions expressed in this article are those of the author and do not necessarily reflect the official policy or position any affiliated agency of the author.

\section{References}

Bamford, J. \& Day, R.R. (eds.), 2004, Extensive reading activities for teaching language, Cambridge University Press, Cambridge.

Bloch, C., 2007, 'Putting little books into little hands in the year of African Languages: Stories across Africa project initiative', in N. Alexander \& B. Busch (eds.), Literacy and linguistic diversity in a global perspective: An intercultural exchange with African countries, pp. 49-62, Council of Europe Publishing, Strasbourg.

Boakye, N.Y., 2017a, 'Efficacy of a reading intervention for first-year university students', A Journal of Language and Learning 33(1), 1-24. https://doi.org/10.5785/33-1-710

Boakye, N.Y., 2017b, 'Extensive reading in a tertiary reading programme: Students' accounts of affective and cognitive benefits', Reading \& Writing 8(1), 1-9. https:// doi.org/10.4102/rw.v8i1.153

Carlisle, J.F., 2000, 'Awareness of the structure and meaning of morphologically complex words: Impact on reading', Reading and Writing 12(3), 169-190. https:// doi.org/10.1023/A:1008131926604

Cekiso, M., 2017, 'Teachers' perceptions of reading instruction in selected primary schools in the Eastern Cape', Reading \& Writing 8(1), a158. https://doi. org/10.4102/rw.v8i1.158

Chall, J.S., Jacobs, V.A. \& Baldwin, L.E., 1990, The reading crisis: Why poor children fall behind, Harvard University Press, Cambridge, MA.

Chambers, A., 2011, Tell me. Children, reading and talk with the reading environment, The Thimble Press, Jackson, MS.

Clark, C. \& Rumbold, K., 2006, Reading for pleasure: A research overview, The National Literacy Trust, London.

Clay, M.M., 1991, Becoming literate: The construction of inner control, Heinemann, Portsmouth, NH.

Daniels, H., 2001, Vygotsky and pedagogy, Routledge, London.

Day, R. \& Bamford, J., 1998, Extensive reading in the second language classroom, Cambridge University Press, New York, NY.

Day, R.R. \& Bamford, J., 2002, 'Top ten principles for teaching extensive reading', Reading in a Foreign Language 14(2), viewed 15 June 2018, from http://www. nflrc.hawaii.edu/rfl/October2002/day/day.html.

Department of Basic Education, 2008, National reading strategy, Department of Basic Education, Pretoria. 
Department of Basic Education, 2012, Curriculum and Assessment Policy Statement (CAPS) Foundation Phase home language grades R-3, Department of Basic Education, Pretoria.

Elley, W.B. \& Mangubhai, F., 1983, 'The impact of reading on second language learning', Reading Research Quarterly 19(1), 53-67. https://doi.org/10.2307/747337

Engestrom, Y., 2011, 'From design experiments to formative interventions', Theory \& Psychology 21(5), 598-628. https://doi.org/10.1177/0959354311419252

Equal Education, 2011, Annual report 2010 \& 2011, viewed May 2020, from https:// equaleducation.org.za/wp-content/uploads/2016/07/Equal-Education-AnnualReport-2010-2011.pdf.

Gambrell, L., 2004, 'Exploring the connection between oral language and early reading', The Reading Teacher 57(5), 490-492.

Grabe, W., 2004, 'Research on teaching reading', Annual Review of Applied Linguistics 24(1), 44-69. https://doi.org/10.1017/S0267190504000030

Grabe, W., 2009, Reading in a second language, Cambridge University Press, New York, NY.

Guthrie, J.T. \& Wigfield, A., 2000, 'Engagement and motivation in reading', in M.L. Kamil, P.B. Mosenthal, P.D. Pearson \& R. Barr (eds.), Reading research handbook, Kamil, P.B. Mosenthal, P.D. Pearson \& R. Barr
vol. 3, pp. 403-424, Erlbaum, Mahwah, NJ.

Howie, S., Venter, E., Van Staden, S., Zimmerman, L., Long, C., Scherman, V. et al., 2007, PIRLS 2006 summary report: South African children's reading achievement, Centre for Evaluation and Assessment, University of Pretoria, Pretoria.

Jacobs, G.M., Renandya, W.A. \& Bamford, J., 2000, 'Annotated bibliography of works on extensive reading in a second language', Reading in a Foreign Language 13(1), 449-489.

Janks, H., 2014, 'Globalisation, diversity, and education: A South African perspective', The Educational Forum 78(1), 8-25. https://doi.org/10.1080/00131725.2014. 850981

Krashen, S., 2004, The power of reading: Insights from the research, 2 nd edn., Heinemann, Portsmouth, $\mathrm{NH}$.

Krashen, S., 2011, 'The compelling (not just interesting) input hypothesis', The English Connection 15(3), 1.

Le Cordeur, M., 2010a, 'The interactive approach to reading instruction: An alternative to traditional ways of teaching reading', Tydskrif vir Geesteswetenskappe 50(1), 104-118.

Le Cordeur, M., 2010b, 'The struggling reader: Identifying and addressing reading problems successfully at an early stage', Per Linguam: A Journal of Language Learning 26(2), 67-76. https://doi.org/10.5785/26-2-23

Malespina, E., 2016, 'An open letter to school boards everywhere', The School Library Journal, May 23, viewed June 2020 from https://www.slj.com/?detailStory=anopen-letter-to-boes-everywhere

Morrow, K. \& Schocker, M, 1987, 'Using texts in a communicative approach', ELT Journal 41(4), 248-256. https://doi.org/10.1093/elt/41.4.248

Morrow, L.M. \& Weinstein, C.S., 1986, 'Encouraging voluntary reading: The impact of a literature program on children's use of library centres', Reading Research Quarterly 21(3), 330-346. https://doi.org/10.2307/747713

Nassimbeni, M., \& Desmond, S., 2011, 'Assessing the impact of provision of books on reading, teaching and learning behaviour in twenty disadvantaged primary schools in South Africa', Proving Value in Challenging Times, York, 22-26 August.
Neuman, S.B. \& Celano, D., 2001, 'Access to print in low- and middle-income communities: An ecological study of 4 neighbourhoods', Reading Research Quarterly 36(1), 8-26. https://doi.org/10.1598/RRQ.36.1.1

Oyegade, E.A., 2012, 'Reading promotion campaign activities of the Oyo State Library Board, Ibadan', in D. Rosenberg (ed.), Reader development and reading promotion: Recent experiences from seven countries in Africa, pp. 73-93, International Network for the Availability of Scientific Publications, Oxford.

Pretorius, E.J., 2002, 'Reading ability and academic performance in South Africa: Are we fiddling while Rome is burning?', Language Matters 33(1), 169-196. https:// doi.org/10.1080/10228190208566183

Pretorius, E.J. \& Knoetze, J.J., 2012, 'The teachers' book club: Broadening teachers' knowledge and building self-confidence', Musaion 31(1), 27-46.

Pretorius, E.J. \& Lephalala, M., 2011, 'Reading comprehension in high poverty schools: How should it be taught and how well does it work?', A Journal for Language Learning 27(2), 2-105. https://doi.org/10.5785/27-2-105

Pretorius, E.J. \& Machet, M., 2004, 'Literacy and disadvantage: Learners' achievements in the early primary school years', Africa Education Review 1(1), 128-146. https:// doi.org/10.1080/18146620408566274

Ramani, E. \& Joseph, M., 2002, 'The communal reading of comics: A case study of an extensive reading project for adult basic literacy', Per Linguam 18(2), 19-30. https://doi.org/10.5785/18-2-127

Richards, J.C. \& Schmidt, R., 2002, Longman dictionary of language teaching and applied linguistics, 3rd edn., Longman, London.

Simon, B., 2018, 'Extensive reading and effects on reading, writing and vocabulary: A literature review', Theoretical and Applied Linguistics at Kobe Shoin 21, 1-10.

Sisulu, E., 2004, 'The culture of reading and the book chain: How do we achieve a quantum leap?', Keynote address at the Symposium on Cost of a Culture of Reading, September 14-17, 2004, National Library of South Africa.

Smith, C., Constantino, R. \& Krashen, S., 1997, 'Differences in print environment for children in Beverly Hills, Compton, and Watts', Emergency Librarian 24(4), 8-9.

Spaull, N., 2014, 'Every child must read', Mail and Guardian, viewed June 2020, from http://mg.co.za/article/2014-11-21-00-every-child-must-read.

Spaull, N., Van der Berg, S., Wills, G., Gustafsson, M. \& Kotze, J., 2016, 'Laying firm foundations: Getting reading right', Research on Socio-Economic Policy (ReSEP), Department of Economics, University of Stellenbosch, viewed n.d., from http:// resep.sun.ac.za/wp-content/uploads/2016/05/ZENEX_LFF-email.pdf.

Taylor, N., 2015, 'Initial Teacher Education Research Project: An examination of aspects of initial teacher education curricula at five higher education institutions', Summary report, JET Education Services, Johannesburg.

Tshuma, L. \& Le Cordeur, M., 2019, 'Intermediate phase mathematics teachers' proficiency in the language of learning and teaching: The Eastern Cape province', Per Linguam 35(3), 106-124. https://doi.org/10.5785/35-3-849

Van Staden, A., 2011, 'Putting reading first: Positive effects of direct instruction and scaffolding for ESL learners struggling with reading', Perspectives in Education 29(4), 10-21.

Vygotsky, L.S., 1978, Interaction between learning and development. From: Mind and society, Harvard University Press, Cambridge, MA. 